\title{
Methodology for the identification of economic, environmental and health criteria for road noise mitigation
}

https://doi.org/10.1515/noise-2022-0002

Received Sep 21, 2021; accepted Nov 09, 2021

\begin{abstract}
The aim of the paper is to define a method for evaluating infrastructural interventions for the mitigation of noise generated by roads based on multi-criteria analysis which considers a series of parameters (environmental, social, economic and health) that could give broader evaluations than just economic convenience.

The research develops a guideline based on an already known methodology applied in other fields, which has been adapted to the above-mentioned topic: the multi-criteria analysis. The decision to use this method originates from an in-depth study of the state of the art regarding the issue of noise pollution related to transport infrastructures in Italy and at a European level.

The Multi-criteria Analysis proved to be the best solution both for completeness and versatility. In particular, the developed methodology uses the Analytic Hierarchy Process as a multi-criteria analysis method. Through its hierarchical structure, this method offers a comparison not only between possible interventions, but also between the same criteria taken into consideration for the choice of the best intervention. The model was validated by analyzing a real noise mitigation project on an Italian main road. The results showed how the model could represent a valid support to decision-making processes.
\end{abstract}

Keywords: transportation noise; noise mitigation; sustainability; health effects; Multi-Decision Criteria Analysis

\footnotetext{
*Corresponding Author: Benedetta Ridolfi: Department of Civil, Constructional and Environmental Engineering, Sapienza University of Rome, 00184 Rome, Italy;

Email: ridolfi.1634275@studenti.uniroma1.it

Francesco D’Alessandro: Italian National Research Council (CNR) Institute on Atmospheric Pollution at Italian Ministry of Ecological Transition, Via Cristoforo Colombo, 44, 00147, Rome, Italy

Paola Di Mascio: Department of Civil, Constructional and Environmental Engineering, Sapienza University of Rome, 00184 Rome, Italy
}

○ Open Access. ( 2022 F. D’Alessandro et al., published by De Gruyter. (Cc) BY 4.0 License

\section{Introduction}

Transport infrastructures are the most significant noise sources in both urban and non-urban areas. According to a report by the European Environment Agency, road traffic noise is the dominant source in the Member States of the European Union, affecting around 100 million people exposed to noise levels higher than $55 \mathrm{~dB} \mathrm{~L}_{\text {den }}$, of whom 32 million are exposed to levels above $65 \mathrm{~dB}$ [1]. In the last two decades the European Commission have adopted measures to limit noise exposure of European citizens and, therefore, emissions generated by road traffic, starting with the publication of the European Directive 2002/49 on Environmental Noise (END) [2]. The recently amended annex III of the END defines harmful effects of noise providing dose/effect relations for ischaemic heart disease, high annoyance (HA) and high sleep disturbance (HSD), which will be implemented in future noise action plans [3].

Even if the European Directive does only consider the harmful effects, the environmental impacts of mitigation intervention are relevant too. This translates into how much an intervention impacts in terms of $\mathrm{CO}_{2}$ emissions or aesthetics on the surrounding landscape. The European Directive also calls for greater involvement of the population, which often underestimates the problem of noise pollution because it is not sufficiently informed and educated. Noise pollution has drawbacks even from the economic and social point of view; for instance, noise affects the market price of dwellings and in general lower socio-economic groups tend to be exposed to higher levels of noise, in particular road traffic noise [4].

There are many different means of road noise abatement, and they vary according to mitigation level required, material used, aesthetic requirements and landscape impact, etc. In general, the measures that are adopted for

Lorenzo Lombardi: Italian National Agency for New Technologies, Energy and Sustainable Economic Development (ENEA) at Italian Ministry of Ecological Transition, Via Cristoforo Colombo, 44, 00147, Rome, Italy 
noise abatement are: noise barriers, porous asphalts, increase of the acoustic insulation of a façade (for instance by means of windows replacement), anti-noise treatment of tunnel portals and anti-noise joints [5-9].

Noise mitigation measures can be quite expensive and usually are not considered a top priority in national policies, including environmental ones. This is because quite often is not State's duty to invest large amounts of money in these works and noise mitigation is handled by private companies managing roads, that are forced to do so to fulfil law requirements. The underestimation of the issue is mainly due to a lack of knowledge both in the general public and in decision makers [10] of the actual effects on human health of noise exposure, thus leading to the little attention that Governments give it compared to other pollutants, despite of the fact that noise is the second most dangerous pollutant after fine particular matter [11].

The research develops a guideline based on an already known methodology applied in other fields, which will be adapted to the above-mentioned topic: the multi-criteria analysis. The already known methodologies tried to become a tool for making a choice based on different heterogeneous elements. The decision to use this method originates from an in-depth study of the state of the art regarding the issue of noise pollution related to transport infrastructures in Italy and at a European level, with reference to the evaluation of costs and benefits; from an economic, environmental, social and health point of view.

The state of the art will present an assessment of the considered analysis, following the criteria adopted and their purpose of application. The adoption of a methodology already used by other States and the comparison of theirs analyses will constitute the starting point.

The goal, at European scale, is to achieve a definite road traffic noise mitigation strategy between the member States.

\section{State of art on the analyses to evaluate the efficiency of noise mitigation measures}

Different existing analyses aimed at evaluating a global efficiency of common noise mitigation measures are evaluated and compared in this section to recognize which aspects needs to be considered, deepened, or included.

A valid selection method should take into consideration the costs of noise abatement measures, including investment and maintenance costs, quantifying the benefits in different terms (economic, social, health, environmental benefits) from different perspectives (benefits for road managers, for urban planners, for politicians, for citizens, etc..) and justifying the choice of the criteria [12-15].

Two extensive studies on the types of analysis have been carried out by CEDR (Conference of European Road Managers) [16] and the European Network of the Heads of Environment Protection Agencies (EPA Network) [17]. The methods proposed by CDER and EPA, summarised in Table 1, differ according to the benefits being considered. Two methods (Cost Effectiveness Analysis and Cost-Benefit Analysis) are common to the two associations.

Table 1: Proposed methods of analysis [17]

\begin{tabular}{ccc}
\hline Method & CEDR & EPA Network \\
\hline Cost Minimisation & & $\mathrm{X}$ \\
Cost Effectiveness Analysis & $\mathrm{X}$ & $\mathrm{X}$ \\
(CEA) & & $\mathrm{X}$ \\
Cost Utility Analysis (CUA) & & $\mathrm{X}$ \\
Cost-Benefit Analysis (CBA) & $\mathrm{X}$ & $\mathrm{X}$ \\
Multi-Decision Criteria & & \\
Analysis (MDCA) & & \\
\hline
\end{tabular}

The Cost Minimisation method considers only one variable: the cost. It evaluates the comparison of mitigation measures that achieve the same results (e.g., by setting a definite noise abatement level as target) and then chooses the cheapest alternative.

The CEA method finds the best noise reduction measures setting predefined objectives. For a given output level, minimises the actual value of costs, or, alternatively, for a given cost, maximises the output level. Once these results have been obtained, they are compared with the so-called "units of effectiveness".

Cost-utilisation analysis (CUA) is similar to CostEffectiveness Analysis (CEA) and is used in health research. The method uses the "Disability Adjusted Life Years" DALY parameter, suggested by the World Health Organisation (WHO) and the World Bank for calculating the productivity lost from road noise exposure [18]. This parameter allows to establish for each clinical phenomenon affected by noise, a weighting that considers mortality, mobility, self-care, discomfort, anxiety, depression.

CBA is an economic calculation method used in transport infrastructures that chooses the best mitigation performance through a global approach in monetary terms. By monetising each effect of the planned interventions, it is possible to quantify them in a unique way and then choose 
the most cost-effective solution. Monetisation is done by associating the benefits of an intervention with a social cost, given by the differences between the baseline scenario and the study scenario. The Revealed Preference approach (RP) was performed for the cost-benefit analysis [17]. The RP approach assumes that the price is set according to environmental characteristics. Noise influences the market price of dwellings in the area polluted by noise. WTP (Willingness To Pay) is estimated by comparing consumer behaviour with different environmental aspects.

Multi-Decision Criteria Analysis combines costs and decision criteria in the evaluation process. An evaluation scale is chosen, and relative weights are assigned for each criterion based on the influence it has on a given mitigation intervention. The optimal solution is the one with the highest weight at the end of the process.

According to EPA Network the optimal method to achieve a common best practice consists of a complete definition of costs and benefits, considering both active and passive mitigation measures. Active interventions are used to reduce the emission of sources and implemented over the medium/long term. Passive measures are used to hinder sound propagation and implemented in the short to medium term. Benefits include health aspects such as reduction of annoyance and sleep disturbance and social acceptability. The unit of measurement for monetisation can be chosen arbitrarily. The inclusion of other secondary criteria will depend on the method adopted; if they are considered, CBA or MDCA analyses will be carried out and become an integral part of the process. These criteria are defined as secondary because they do not have the direct aim of balancing costs and benefits, but they are nevertheless essential for a decision that encompasses several areas at once. The other criteria are: safety, technical limitations, reliability, maintenance and availability, effects on mobility and capacity, social, cultural, aesthetic criteria, policy and public acceptance [17].

Each analysis has strengths and weaknesses which make them feasible in different contexts depending on the time and budget available. Other factors that determine the choice of the best decision-making method are related to the size of the noise problem; some methods are more easily implemented on small projects and others on largescale projects. A simple cost minimisation analysis might be sufficient in a small project. A more in-depth investigation, on the other hand, might lead to the choice of cost effectiveness analysis (CEA), cost utility analysis (CUA) and cost benefit analysis (CBA).

\section{Material and methods}

This study aims to define an evaluation model for the choice of the best acoustic mitigation intervention in the context of road infrastructures. The peculiarity of each context increases the difficulty of comparing different mitigation measures. The application of a methodology that links general aspects such as economics, health, environment, social aspects with noise mitigation techniques is therefore proposed, also aiming at a gradual and strategic adaptation to principles contained in the Italian Legislation (article 26 of the Legislative decree no. 42, dated 17 February 2017) [19].

The model presented in this study was developed using a multi-decision criteria analysis (MDCA) methodology. The complexity of the choice of intervention and the number of possible criteria related to it define MDCA as the best analysis to combine these aspects. The research objective is to implement the starting point for a complete and indepth study of noise mitigation interventions for transport infrastructures. The difficulty in assessing criteria such as sustainability has identified MDCA as a good solution to encompass different fields and guarantee a comparison among different types of noise mitigation measures for road infrastructures.

\subsection{Multi-decision methods and Analytic Hierarchy Process}

The multi-decisions analysis allows the use of heterogeneous criteria whose importance is established by weights. These weights are established not only by the relationship of a criterion to topical issues, but also by the correlation that exists between one criterion and another; furthermore, the use of such variables is closely linked to the national policy of a country, which makes it possible to prioritise a particular issue and highlight institutional purposes in a particular field.

There are various methods for multi-decisions analysis related to its use in various applications; one of the most popular is the Analytic Hierarchy Process (AHP) developed by the Iraqi mathematician Thomas L. Saaty. This method has been used in many fields [20-24] due to its flexibility. Indeed, this technique allows several alternatives to be compared, in relation to qualitative and quantitative criteria, obtaining a global evaluation for each of them. Saaty offers a methodology that breaks down the problem into elements (Analytic), creates a hierarchical structure of these by setting an objective (Hierarchy) and processes them to arrive at a result (Process). In this way, there is no absolute 
evaluation, but a global and comparable view in terms of efficiency [25]. The method can be summarised in three steps:

Step 1: Creation of a hierarchical structure by breaking down the decision problem into sub-problems, which are defined as criteria and alternatives. The first level of the hierarchical structure represents the overall "goal" of the analysis; the final level represents the alternatives to be considered; the intermediary levels represent criteria and sub criteria for evaluating the alternatives. All possible solutions are defined as decisions.

Step 2: The relative importance of criteria and alternatives, at the same or higher level, is established through pairwise comparison. The answer could be quantitative in case of objectively comparable data or, when this is not possible, a numerical scale such as the one in Table 2 is used.

Table 2: Saaty's scale [25]

\begin{tabular}{cc}
\hline Judgment & Relevance scale \\
\hline 1 & Identical \\
2 & \\
3 & Weak \\
4 & \\
5 & Significant \\
6 & \\
7 & Storng \\
8 & \\
9 & Absolute \\
\hline
\end{tabular}

Pairwise comparison matrices are created where each element $m_{i j}$ represents the preference of $i$ over $j$ and the element $m_{j i}$ is reciprocal. The matrices created are square, symmetrical, and diagonal and have the same size as the number of elements considered at each level. Scores are established as impacts of alternatives on decisions. The matrix is normalised by dividing each score by the sum of the scores in its column, defining $x_{i j}$ as the generic element of the normalised matrix:

$$
x_{i j}=\frac{c_{i j}}{\sum_{j=1}^{m} c_{i j}}
$$

The weight $w_{i j}$ of each decision is a weighted average of the scores of each alternative on the decision, and it is equal to:

$$
w_{i j}=\frac{\sum_{j=1}^{m} x_{i j}}{m}
$$

Step 3: The weight of the $\mathrm{n}$-th decision is multiplied by the weight of the alternative and by the weight of the criterion to which the alternative belongs. The result is added to the scores calculated for the subsequent criteria. The choice between the decisions is represented by the one with the highest score. Through this type of hierarchical analysis, objective and subjective evaluations can be considered. The former is linked to the score that is established among the various alternatives; the latter is determined by the weight that the decision-maker assigns to each criterion. The method is complex and multi-faceted, but at the same time flexible and inclusive of many aspects.

\subsection{Analytic Hierarchy Process applied to noise mitigation selection}

The present paper presents the application in a real case study of the AHP method for choosing the best type of intervention for the abatement of noise from a road infrastructure.

In level I, the "main goal", the objective of the analysis is to find the best mitigation action for a given area to be restored. In level II the criteria on which the choice depends are clearly defined. In this case, four parameters are considered: environmental, economic, health and social. In level III, the different alternatives for each criterion are examined:

- Environment: noise abatement expressed in $\mathrm{dB}(\mathrm{A})$, landscape and visual impacts, visibility limitation (i.e. how much of the view is precluded by the intervention for the dwellers, common for a noise barrier) and emission of carbon dioxide over its life cycle;

- Economy: cost, including operation and maintenance, and social cost, i.e. the influence of the noise climate of the area on the housing price [26];

- Health: the harmful effects of noise on human health such as cardiovascular disease, tinnitus, sleep disturbance (only considered in the nighttime analysis) and annoyance;

- Social: intervention acceptability by the population.

This hierarchical division is summarised in Figure 1.

The possible interventions considered become a function of the number, quality, and the hierarchy assigned to the chosen alternatives. Each of these ones must maximise or minimise an aspect that a mitigation intervention presents in the context in which it is placed. The choice is 


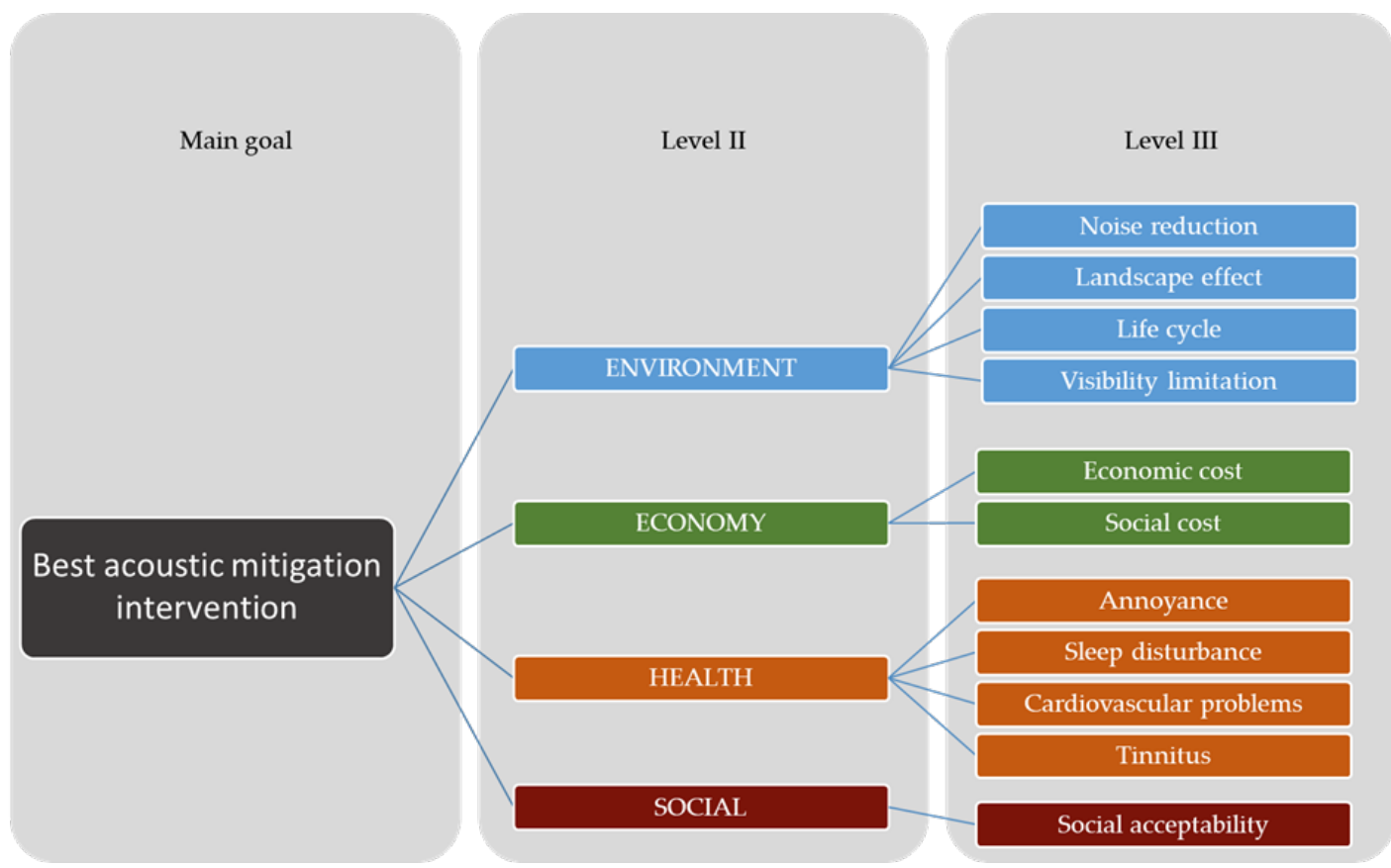

Figure 1: Hierarchical decomposition of AHP

made according to the relative objectives divided by each criterion:

- Environment:

- Maximisation of noise reduction, in terms of $\mathrm{dB}(\mathrm{A})$;

- Minimisation of landscape impact;

- Minimisation of $\mathrm{CO}_{2}$ emissions;

- Maximising visibility (i.e. minimizing visual obstruction).

- Economy:

- Minimisation of the cost, including construction, operation and maintenance cost;

- Maximising the percentage value of price increase in housing costs.

- Health:

- Maximising the decrease in relative risk of cardiovascular disease and tinnitus;

- Maximisation of absolute risk reduction for sleep disturbance and discomfort;

- Social:

- Maximising social acceptability.

The weighting of the Level II criteria (Figure 2) and the Level III environmental and economic alternatives (Figures 3 and 4) was determined by analysing the responses to a survey submitted to experts in this fields. The ana-

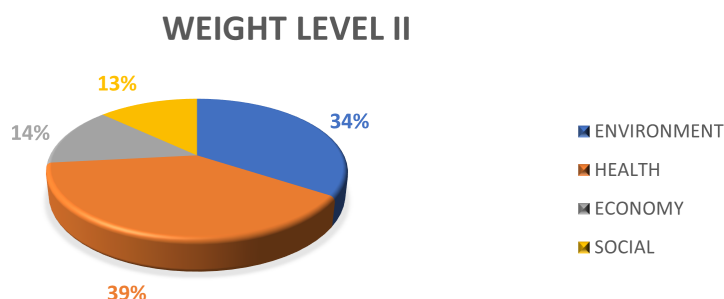

Figure 2: Weights level II

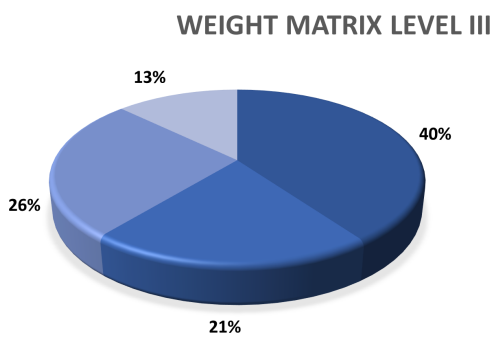

a NOISE REDUCTIO - LANDCAPE EFFECT - LIFE CYCLE a VISIBILITY LIMITATION

Figure 3: Weights level III (environment)

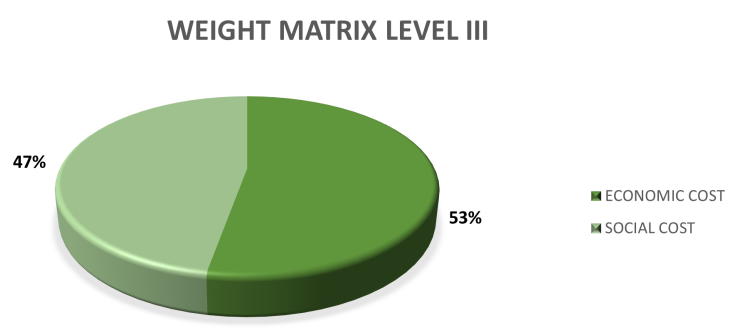

Figure 4: Weights level III (economy) 
lyzed sample consists of 41 experts coming from heterogeneous fields such as: La Sapienza University of Rome, Ministry of the Ecological Transition, ANAS S.p.A. (formerly an acronym for National Autonomous Roads Corporation), Regional Agencies for Environmental Protection (ARPA) and experts in acoustics.

The SARS-CoV-2 pandemic did not allow for adequate public involvement regarding survey administration. For this reason, the choice was to privilege a limited number of experts instead of a large number of people.

The survey affects the flexibility of this method as it depends on the variability of the weights determined by the opinion of the experts.

The matrix of level III weights for environment and economy is defined (Figures 3 and 4, respectively), through six comparative questions between the six alternatives of each of the two criteria (environment and economy). The response is made by a 5-point Likert scale ranging from a score of 1 for a "strongly disagree" response to a score of 5 for a "strongly agree" response.

As shown in Figure 3, the noise abatement, within the environment criterion, is the most crucial alternative, being given priority with a percentage value of $40 \%$ compared to the other elements considered. This is also due to the need, especially felt by the officers of the Ministry, to bring the sound pressure levels within the legal limit.

In the survey, the quantification of the level of acceptability of the various proposed mitigation measures should have been assess by the population living in the project area, but the movement restrictions caused by SARS-CoV-2 pandemic did not allow this. Therefore, the part regarding the acceptability of the mitigation measures was submitted only to the experts and they were only asked how much the commonly used mitigation measures are accepted according to a 5-point Likert scale ranging from "a little" to "a lot". Answers are influenced by experts' knowledge and culture, so a high weighting of acceptability results to sound insulating windows. However, this type of intervention involves replacing existing windows on private property which in many cases is not accepted by citizens.

The level III weights for the health criteria were derived from data provided by the World Health Organisation (WHO) based on the Burden of Disease from Environmental Noise [11]. The data were elaborated to calculate the health burden of disease due to long-term exposure to noise from transport infrastructure. In the case of this study, it was considered only the part concerning road vehicle traffic as a source of noise and the data referring to Italy [27]. This data was used to calculate the DALY value for each harmful effect considered [10, 11].
The data needed concerned:

- total Italian population updated to 2015 [27];

- the population exposed to $5 \mathrm{~dB}$ bands (50-59, 60-64, 65-69, 70-74, >75) for $L_{d e n}$ and $L_{\text {night }}$, respectively;

- the absolute and relative risk values for each harmful effect with dose-effect relationships take from the WHO Environmental Noise Guidelines [10];

- disability factors for each harmful effect [11].

In the AHP analysis, for simplicity of calculation, only four of the harmful effects correlated with noise exposure (cardiovascular problem, annoyance, sleep disturbance, tinnitus) were considered. This choice was based on the availability of data and possible correlations with the purpose of the study. Figures 5 and 6 show the graphs of the weights for the health criterion obtained through the matrices developed for nighttime and daytime.

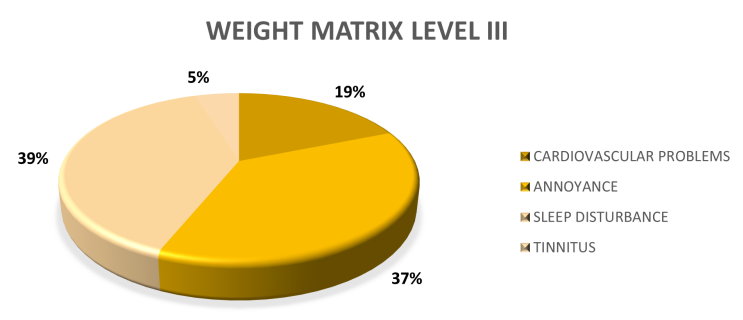

Figure 5: Level III weights (nighttime health)

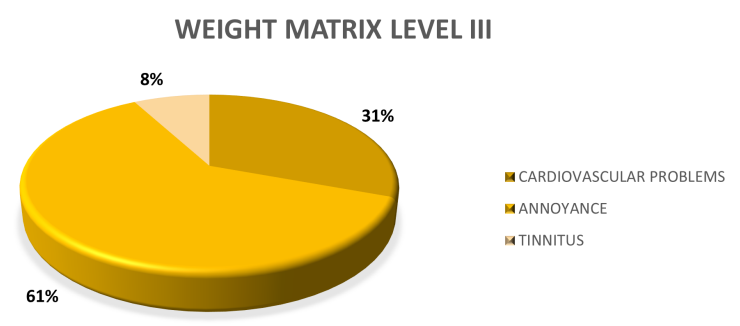

Figure 6: Level III weights (daytime health)

\section{Case study}

The presented method was validated on a project of noise mitigation interventions in the surrounding of a road infrastructure. The case study is a section, approximately $1 \mathrm{~km}$ long, of via Appia (S.S. 7), a single carriageway road with two lanes per direction within the Municipality of Albano Laziale, near Rome in Italy. 
The road crosses an area with several buildings, including some schools. The absence of overlapping with other infrastructural noise sources, the heterogeneous urban context and the multiplicity of remedial actions present in the project provided important elements for the validation of the model.

The road manager calculated the exceeding of the noise limits, both during the day and the night, at 1 metre from the façade of buildings along the road, according to the Italian legislation. The receptors are divided into (Figure 7):

- Residential, shown in light blue;

- Non-residential, in grey;

- Schools, in pink.

The dashed and dotted orange lines in Figure 7 represent the so called "strips of acoustic relevance" introduced by the Italian legislation [28]: in the one closer to the road (100 m wide) the daytime (06-22) and nighttime (22-06) noise limits are respectively 70 and $60 \mathrm{~dB}(\mathrm{~A})$, while in the one farer from the road (150 m wide) they are respectively 65 and $55 \mathrm{~dB}(\mathrm{~A})$. In both strips, in cases of building requiring conditions of quiet, usually called sensitive buildings, including schools, hospitals and retirement homes, noise limits are reduced to $50 \mathrm{~dB}(\mathrm{~A})$ for the daytime period and $40 \mathrm{~dB}(\mathrm{~A})$ for the nighttime period.

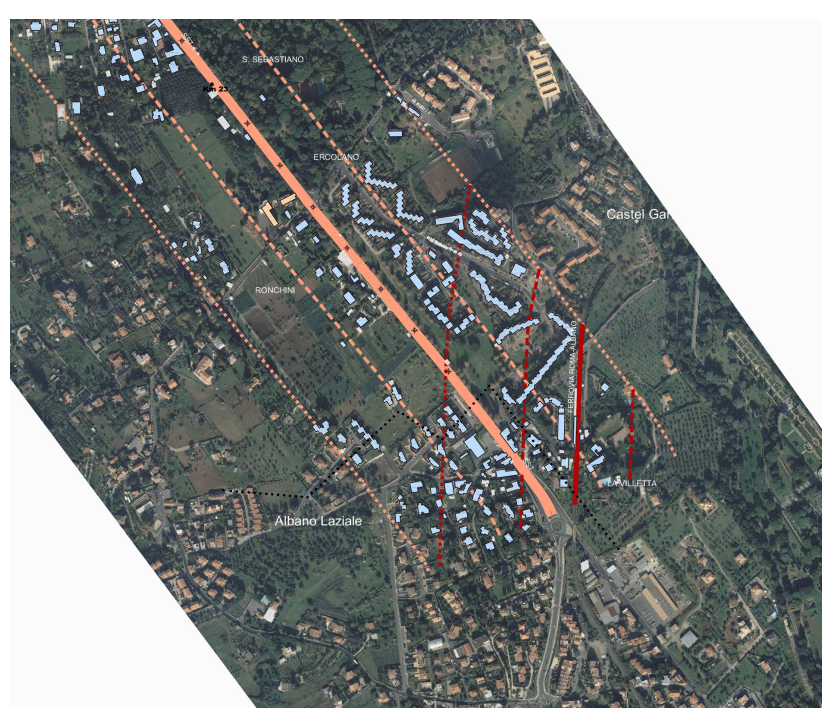

Figure 7: Site plan

The given exceedance is the one representing the high est noise level calculated on the various floors of the dwellings. On 119 coded receptors considered, 6 buildings, including two school buildings, exceed the limits in the daytime scenario and 17 in the nighttime scenario. The disparity between the two configurations is justified by various factors: the difference in traffic flows and speed assumed by vehicles during the night and, above all, the difference in the Italian legal limit values for road traffic noise between the daytime and nighttime periods.

The acoustic mitigation measures to implement the reclamation plan envisaged by the managing authority are threefold:

- low-noise road surface for the entire stretch;

- direct interventions on receptors (replacement of windows), foreseen for seven buildings, two of which are school buildings;

- $2 \mathrm{~m}$ high noise barriers in correspondence of one building.

\subsection{Application of the Analytic Hierarchy Process to the case study}

The "Step 1" of the AHP method (as described in 3.1) is the definition of the "main goal" or the level I of the AHP, that is the research of the best mitigation action for the considered area.

The application of the AHP analysis model involves two scenarios. Each one is characterised by an average exceedance value. The average exceedance values are calculated using population data provided by the Italian Institute of Statistics [29]. For each census area the resident population and the characteristics of the present buildings, i.e. number of floors and components per building, has been studied. The area of the 17 buildings with noise exceedances was calculated, each multiplied by the number of floors and the population density, and the dwellers average number was calculated for the nighttime configuration. For the daytime configuration, the same steps for the 6 exceedance buildings were followed. The population density was calculated as the inverse of the ratio between the total area of buildings within a census section, and the area of the section itself.

$$
n=\left(\frac{p \cdot r}{t}\right)
$$

where:

$n=$ number of current people;

$p=$ walkable area calculated with the software GRASS GIS;

$r=$ numbers of floor for each building [29]; $t=$ population density expressed in square metre per person, the value 50 square metre per person has been chosen.

The summation of the number of current people for the exceedance value for all buildings, divided by the total exposed population gave the average exceedance:

$$
a=\frac{\sum_{1}^{z}(n \cdot b)}{c}
$$


where:

$a=$ average exceedance;

$n=$ number of current people (3);

$b=$ building exceedance $\left(z_{o}\right)$;

$c=$ total population exposed.

The average exceedance value at night is $3.5 \mathrm{dBA}$ and the average exceedance value during the day is $8.3 \mathrm{dBA}$. School buildings are only considered in the daytime scenario and, as prescribed by the Italian legislation, a multiplication coefficient that considers the number of pupils inside the school has been used in the calculation of exposed persons. The coefficient used was set to 3 in accordance with the Italian law [30].

After calculating the average exceedance values, the mitigation measures to be considered in the analysis were chosen, differing in type, materials used and type of intervention. Combinations of measures are not considered in this study. The selected mitigation measures are:

I. Ventilated insulating windows. Insulating windows are self-ventilating and equipped with an aerator that allows air to flow through the window. Its cost is estimated at $€ 750$ per windows square metre [6].

II. Porous asphalts. The average cost is estimated at 120 euros per cubic metre; for the case study the pavement of the entire road stretch will be replaced with low-noise one [6].

III. Noise barriers. Six types have been chosen, with different types of material used. All are assumed to be 4 metres high. The price list provided by the Italian public road manager (ANAS, 2017) was used for the cost estimate. The analysed types of noise barriers are:
a. glass barrier;
b. aluminium barrier;
c. mixed aluminium and glass barrier;
d. mixed aluminium and PMMA (polymethyl- methacrylate) barrier;
e. mixed steel and glass barrier;
f. mixed steel and PMMA barrier.

IV. Reduction in traffic flows. The estimate of traffic flows was obtained from the information available on the Lazio Region website [31]. Two traffic reduction scenarios are considered in the study: the elimination of heavy vehicles or a generic 50\% reduction. The calculated cost refers exclusively to the use of road signs as access prohibitions per vehicle category.

V. Speed reduction. A speed reduction to $70 \mathrm{~km} / \mathrm{h}$ is assumed. In the cost calculation it is assumed that only signage is used at the beginning and end of the section and at the point where there is an intersection on both sides.

Once the actions that can be implemented and the average exceedance values in the night and day configurations have been established, the matrices linking the possible decisions with each alternative present in the hierarchical decomposition can be constructed.

Four alternatives are proposed for the environment criterion: noise abatement, landscape impact, life cycle and visibility limitation. The abatement values for each proposed intervention were established based on the indications provided by the European project NADIA [32]. In the table below the costs and rebates for each type of intervention:

Table 3: Cost and noise abatement for each intervention [32]

\begin{tabular}{ccc}
\hline $\begin{array}{c}\text { Noise mitigation } \\
\text { intervention }\end{array}$ & $\begin{array}{c}\text { Economic } \\
\text { cost } \\
\left(€ \text { per } \mathrm{m}^{2}\right)\end{array}$ & $\begin{array}{c}\text { Noise } \\
\text { abatement } \\
(\mathrm{dBA})\end{array}$ \\
\hline $\begin{array}{c}\text { Ventilated insulation } \\
\text { window }\end{array}$ & 750 & 10 \\
$\begin{array}{c}\text { Porous asphalts } \\
\text { Noise barrier (glass) }\end{array}$ & 30 & 3 \\
Noise barrier (aluminium) & 275 & 10 \\
$\quad$ Noise barrier & 258 & 13 \\
(aluminium+glass) & & 11 \\
$\quad$ Noise barrier & 250 & 11 \\
$\quad$ (aluminium+PMMA) & & \\
Noise barrier (steel+glass) & 280 & 10 \\
Noise barrier (steel+PMMA) & 270 & 10 \\
Reduction of traffic flow & 0.07 & 1 \\
$\quad$ (heavy vehicles) & & \\
Reduction of traffic flow 50\% & 0.07 & 2.5 \\
Speed reduction $70 \mathrm{~km} / \mathrm{h}$ & 0.07 & 2 \\
\hline
\end{tabular}

\section{Results}

The matrix, which links the noise abatement with the possible decisions, is constructed by considering eligible interventions that produce the greatest reduction in $\mathrm{dB}(\mathrm{A})$. During the study the average exceedance required was also included in the calculation of the assigned score. The pairwise comparison in terms of abatement will therefore not only be the ratio between the values but the ratio between the difference of the values and the average exceedance, 
thus highlighting the importance of the relativity of a result with respect to the context:

$$
\frac{r_{i}-a}{r_{j}-a}
$$

where:

$a=$ average exceedance (4);

$r=$ noise reduction.

For each ratio value, a score is assigned according to Saaty's scale. The matrices, day and night scenario, are normalised. The weight matrix is obtained by means of the weighted average, "Step 2" of the AHP method.

Figure 8 shows the relativity of the result, introduced earlier, to the context of the two scenarios, i.e. daytime and nighttime period. Porous asphalts or the reduction of traffic by $50 \%$ in the daytime analysis have a low percentage because they are very far from the average value, in the nighttime scenario they are less effective than interventions such as barriers but still valid with a percentage double that of the opposite scenario.

Considering the aesthetic impact of an intervention on the landscape is the objective of the second alternative proposed. The scoring was carried out by taking as a reference the assessments made in the NADIA project [32].

The environmental criterion cannot be separated from an alternative that considers how much a mitigation measure impacts emissions over its life cycle. Within the European standard EN 15804 [33] it indicates which life cycle phases are present in the EPD (Environmental Product Declaration), which environmental indicators must be declared and how they are collected. One of these is the Global Warming Potential (GWP) chosen to link mitigation actions with the life cycle alternative.

For ventilated insulating windows, the GWP calculation was derived from the LCA of the model chosen for the case study available on the EnvironDec website, using the

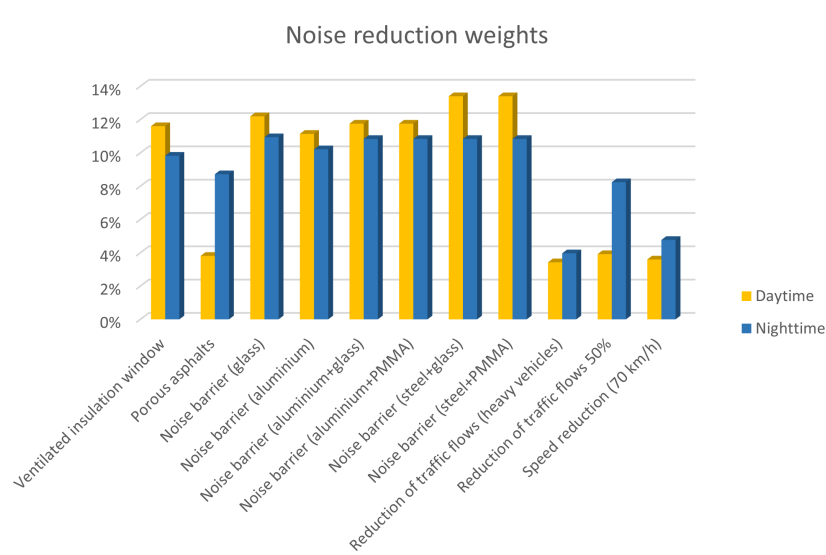

Figure 8: Comparison of noise abatement weights in the two scenarios
Simapro programme with Ecoinvent 2.0 database [34]. For porous asphalt, an analysis was carried out on SimaPro to derive the GWP 100. For barriers, a study carried out by the Brero et al. [35] on the sustainability of noise barriers was used. The environmental indicators, used for the EPD calculation, of 16 types of panels differing in material, height and length were compared. For the reduction of traffic flows a neutral value was assumed as there is no saving of emissions and the traffic is only diverted to other routes. For the speed reduction intervention, the data is approximately $250000 \mathrm{~kg}$ of $\mathrm{CO}_{2}$ saved in 100 years by imposing a speed of $70 \mathrm{~km} / \mathrm{h}$. Once calculated, they were transformed into $\mathrm{GWP}$, i.e. $\mathrm{kg}$ of $\mathrm{CO}_{2}$ equivalent. A study by the National Association of Telematics for Transport and Safety was used to calculate emissions [36].

Table 4 contains the GWP values for the interventions considered. Speed reduction is characterized with a negative value as the only intervention with no-production of $\mathrm{CO}_{2}$ equivalent.

The scores assigned in the pairwise comparison matrix involve the use of Saaty's scale, with the highest value being assigned to the speed reduction intervention. Table 5 lists

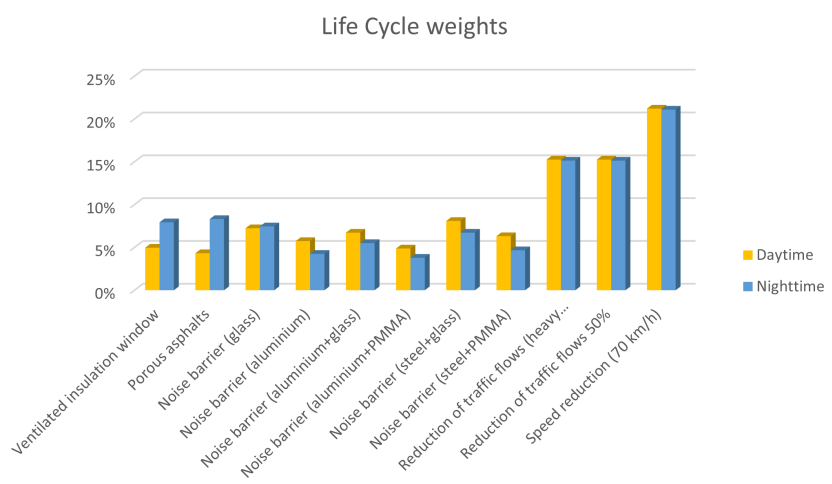

Figure 9: Comparison of life cycle weights in the two scenarios

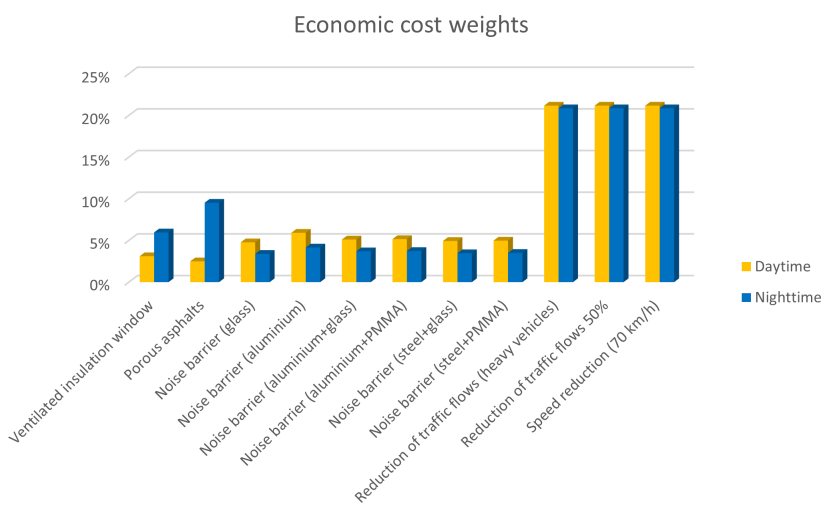

Figure 10: Comparison of economic cost weights in the two scenarios 
Table 4: GWP values for mitigation actions in the two scenarios

\begin{tabular}{|c|c|c|}
\hline INTERVETIONS & $\begin{array}{l}\text { LIFE CYCLE (GWP-Kg CO } \mathrm{CO}_{2} \text { eq.) } \\
\text { daytime }\end{array}$ & $\begin{array}{l}\text { LIFE CYCLE (GWP-Kg } \mathrm{CO}_{2} \text { eq.) } \\
\text { nighttime }\end{array}$ \\
\hline Ventilated insulation windows & 90017 & 224350 \\
\hline Porous asphalts & 242812 & 242812 \\
\hline Noise barriers (glass) & 38064 & 209840 \\
\hline Noise barriers (aluminium) & 81120 & 447200 \\
\hline Noise barriers (aluminium+glass) & 59592 & 328520 \\
\hline Noise barriers (aluminium+PMMA) & 93600 & 516000 \\
\hline Noise barriers (steel+glass) & 51792 & 285520 \\
\hline Noise barriers(steel+PMMA) & 85800 & 473000 \\
\hline Reduction of traffic flows (heavy vehicles) & 1 & 1 \\
\hline Reduction of traffic flow $50 \%$. & 1 & 1 \\
\hline Speed reduction $(70 \mathrm{~km} / \mathrm{h})$ & -281652 & -153189 \\
\hline
\end{tabular}

Table 5: Weight matrix for life cycle, day and night scenario

\begin{tabular}{ccc}
\hline LIFE CYCLE & DAYTIME WEIGHT & NIGHTTIME WEIGHT \\
\hline Ventilated insulation windows & 0.050 & 0.079 \\
Porous asphalts & 0.043 & 0.083 \\
Noise barriers (glass) & 0.072 & 0.075 \\
Noise barriers (aluminium) & 0.057 & 0.042 \\
Noise barriers (aluminium+glass) & 0.067 & 0.055 \\
Noise barriers (aluminium+PMMA) & 0.049 & 0.038 \\
Noise barriers(steel+glass) & 0.081 & 0.067 \\
Noise barriers(steel+PMMA) & 0.063 & 0.047 \\
Reduction in traffic flows (heavy vehicles) & 0.153 & 0.151 \\
Reduction of traffic flow 50\%. & 0.153 & 0.151 \\
Speed reduction (70 km/h) & 0.212 & 0.210
\end{tabular}

Table 6: Values assigned for reduced visibility

\begin{tabular}{c|c}
\hline $\mathbf{1}$ & $\begin{array}{c}\text { Ventilated insulation window porous asphalts } \\
\text { reduction of traffic flow (heavy vehicles and 50\%) } \\
\text { s.5 }\end{array}$ \\
$\mathbf{0}$ & Noise barrier (glass) \\
& Noise barrier (steel+PMMA) \\
& Noise barrier (aluminium) \\
& Noise barrier (aluminium+glass) \\
& Noise barrier (steel+glass) \\
& Noise barrier (aluminium+PMMA \\
\hline
\end{tabular}

the weight matrix for the two scenarios respectively, after normalising.

The difference in the two scenarios shows, in Figure 9, how interventions take on different importance depending on the context. For asphalt, which produces the same amount of GWP in both scenarios, a greater weight is given

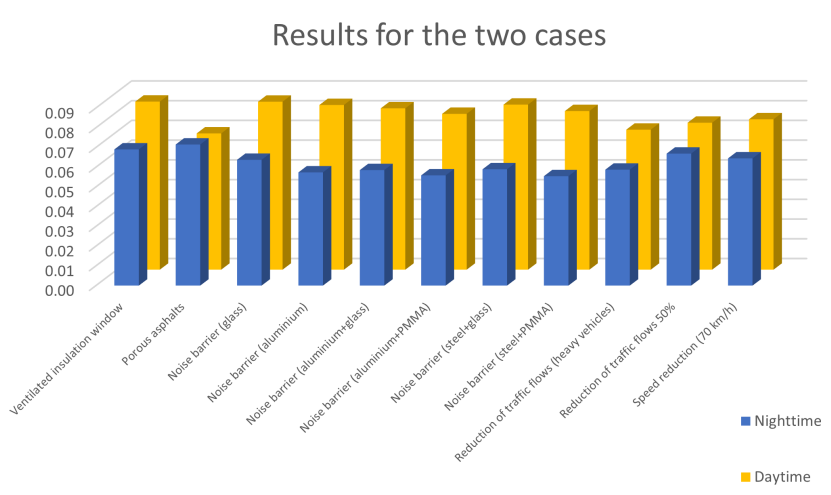

Figure 11: Results for the two cases

to the night scenario as the other interventions show a large difference in GWP between the day and night scenarios.

The last alternative considers how much a mitigation intervention hinders sight for the dwellers. The attribution of the score has been assumed, in a simplified way, attribut- 
ing a value equal to 1 for interventions that do not limit visibility, 0 for those that completely obstruct the view and 0.5 for intermediate cases as reported in Table 6 .

Figure 10 shows the comparison between the two scenarios for the economic cost, the most evident differences concern interventions such as windows and asphalts, since in the night scenario these types of intervention prove to be more economical than noise barriers.

In addition to the economic cost, the social cost is also considered. For the latter, the Willingness To Pay (WTP) is used. The WTP expresses the price that people are willing to pay to live in a quieter noise environment and it is estimated by considering a depreciation of dwellings of $0.49 \%$ for every $1 \mathrm{~dB}$ increase above the $55 \mathrm{~dB}$ threshold [26].

For the health criterion, four alternatives were considered: cardiovascular problems, tinnitus, sleep disturbance and annoyance. The WHO gives a relative risk per $10 \mathrm{~dB}$ increase per type of infrastructure for cardiovascular problems and tinnitus [10]. For the other two alternatives no values are given directly; Annex 3 of European Directive
2002/49 is used [2], as amended by Commission Directive (EU) 2020/367 of 4 March 2020 where the formulas are given for the risk value calculation (3).

Summing up ("Step 3" of the AHP method, described in 3.1) the results of all criteria for each decision, the best mitigation intervention is estimated, which corresponds to the one with the highest value.

The criteria taken individually favour different interventions: for the social criteria, the best intervention is the use of porous asphalt, while in the health criterion the best intervention is opaque noise barriers. For criteria such as environment and economy, as they consist of many alternatives, the intervention with the greatest weight may differ depending on the scenario considered. Considering the 4 aspects as a whole, the result is quite different, showing how the simultaneous analysis of all factors to meet the needs of respect and protection of the environment and economic and social sustainability leads to different and more complete evaluations.

\section{Best mitigation intervention}

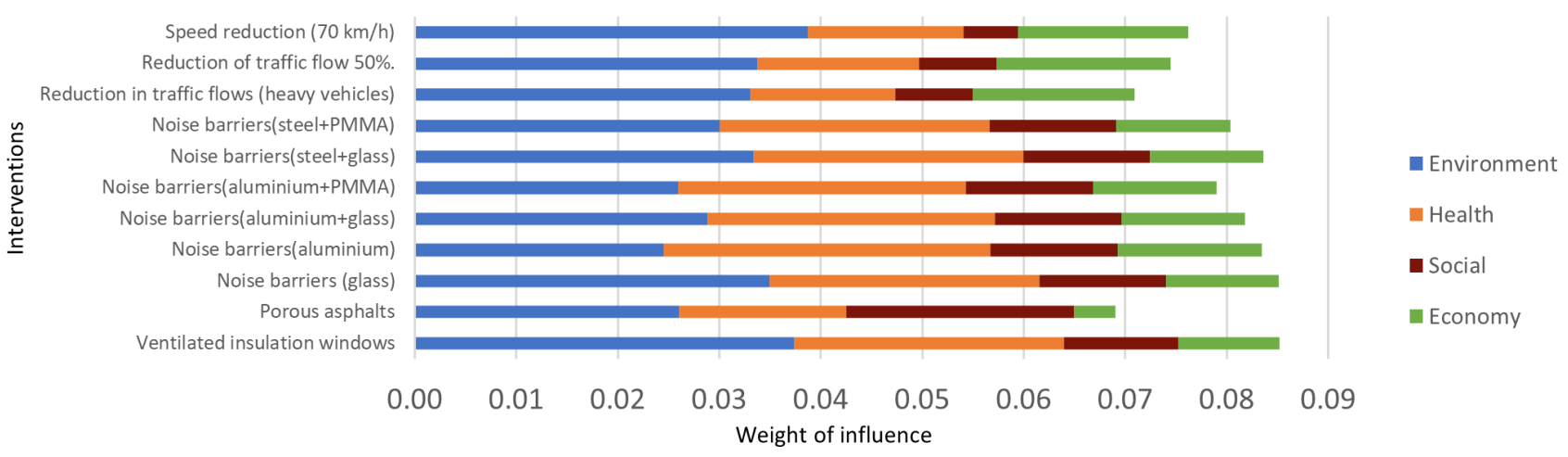

Figure 12: Analysis results for the daytime scenario

\section{Best mitigation intervention}

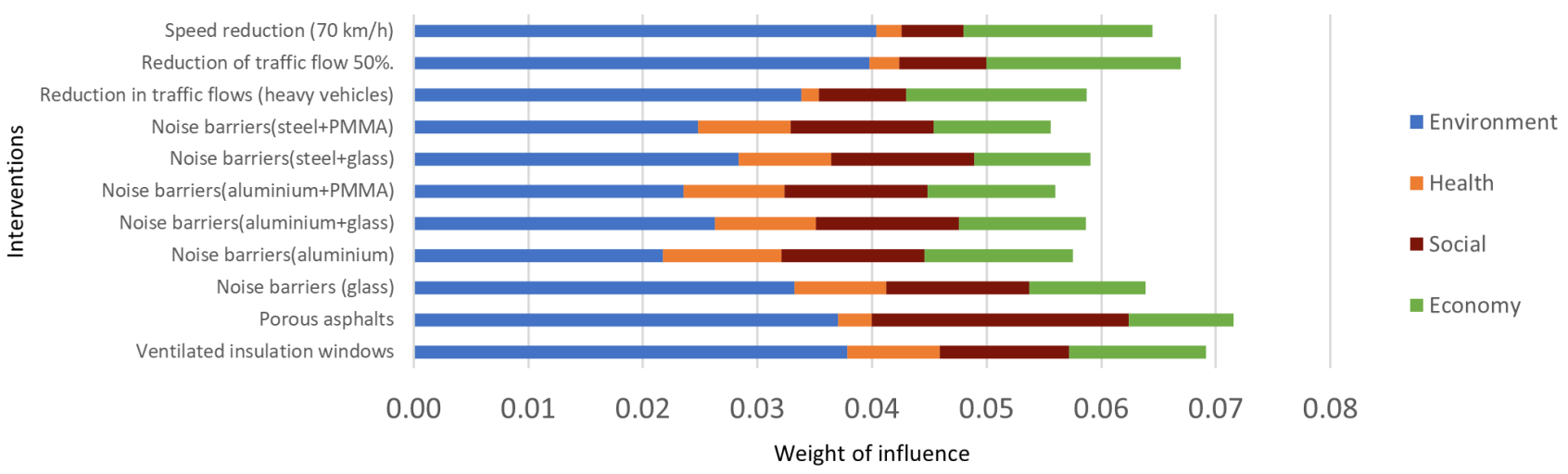

Figure 13: Analysis results for the nighttime scenario 
Figure 11 shows the results for the night and day scenarios respectively, where the shown values represent the sum of the contributions of each criterion. Examining in detail the results for the two configurations, the intervention that has the highest weight in the daytime scenario is the use of insulating windows (Figure 12), for the nighttime scenario the best result is for the use of porous asphalt (Figure 13).

The results are in line with the choice of acoustic remediation for most of the buildings with exceedances planned by the road manager authority. As already mentioned, the results are also variable depending on the choice of parameters considered for each alternative. In detail, significant changes could depend on: the consideration of other environmental indicators, the enlargement of the involvement of the population affected by the project interventions, the creation of different questionnaires for each type of interviewed sample, the addition of other evaluation criteria.

\section{Conclusions}

This study proposes a method for evaluating infrastructural interventions for the mitigation of noise produced on roads based on multi-criteria analysis and considers a series of parameters (environmental, social, economic and health) that could give broader evaluations than just economic convenience. The Italian legislation [19] on noise pollution already requires, in a generic way, the need to consider such parameters in the choice of mitigation measures. The existing studied models led to create a european vision projected guide. The different analyses have been evaluated based on their applications in some of the $\mathrm{Eu}$ ropean countries. The Multi-criteria Analysis proved to be the best solution both for completeness and versatility. In particular, the developed methodology uses the AHP (Analytic Hierarchy Process) as a multi-criteria analysis method. Through its hierarchical structure, this method offers a comparison not only between possible interventions, but also between the same criteria taken into consideration for the choice of the best intervention. The model was validated by analysing a noise mitigation project on an Italian road. The results showed how the model represents a valid support to decision-making processes for clients, managing bodies, designers and all those who have the duty of a broader vision. Above all this vision must be shared with and be for the population. It is an expression of the more and more necessary connection between "works" and people, between the man-made and the human nature.

Even if this methodology represents a first attempt at evaluation, it provides quantitative indications on the best intervention to be used to obtain an acoustic improvement considering the whole project. The analysis is general and comprehensive and provides solutions applicable to many buildings that must be acoustically upgraded and a guideline for intervention, ensuring that these choices are no longer focused on a single objective (economic), but aiming to assess also criteria that can no longer be underestimated such as environmental, health and social criteria.

To strengthen this study and make it even more effective, it is necessary as a future development to consider the inclusion of other evaluation criteria and the use of other parameters for comparing the different alternatives. It is also necessary to develop questionnaires for each type of sample interviewed, involving not only experts but the population who is the one exposed to noise.

Acknowledgement: The authors gratefully thank Patrizia Bellucci and Laura Peruzzi (ANAS S.p.A.) for their support in selecting the case study and providing all the relevant data about noise mapping and mitigation plan, Giovanni Brero (UNICMI - Italian National Union of Industries of Metallic Construction, Building Envelopes and Windows) for the fruitful discussions on noise mitigation measures and for the documents concerning noise barriers. A word of thanks to Lucia Pasini (Italian National Research Council - Institute on Atmospheric Pollution at Italian Ministry of Ecological Transition) for providing useful information about ongoing activities at the European Commission concerning noise related health effects and Professor Laura Moretti (Department of Civil, Constructional and Environmental Engineering, Sapienza University of Rome, 00184 Rome, Italy) for her contribution to the calculation of $\mathrm{CO}_{2}$ emissions for pavements.

Funding information: The authors state no funding involved.

Author contributions: All authors have accepted responsibility for the entire content of this manuscript and approved its submission.

Conflict of interest: The authors state no conflict of interest.

\section{References}

[1] European Environment Agency. Managing exposure to noise in Europe. [Online]. 2019. Available from: https://www.eea.eu ropa.eu/publications/environmental-noise-in-europe 
[2] European Parliament and the Council. Directive 2002/49/EC relating to the assessment and management of environmental noise. 2002 June 25.

[3] European Commission Directive 2020/367. Amending Annex III to Directive 2002/49/EC of the European Parliament and of the Council. 2020 March 4.

[4] European Environment Agency. Unequal exposure and unequal impacts: social vulnerability to air pollution, noise and extreme temperatures in Europe. 2018.

[5] Brown AL, Van Kamp I. WHO Environmental noise guidelines for the European Region: A systematic review of transport noise interventions and their impacts on health. Int J Environ Res Public Health. 2017;14(8):873. https://doi.org/10.3390/ ijerph14080873.

[6] Conte A, D'Alessandro F, Schiavoni S. The contribution of LIFE+ NADIA project on the implementation of the European Directive on Environmental Noise. Noise Mapp. 2015;2(1):13-30.

[7] Nilsson M, Bengtsson J, Klaeboe R. Environmental Methods for Transport Noise Reduction. Boca Raton, London, New York: CRC Press; 2019.

[8] HOSANNA Project. Novel solutions for quieter and greener cities; 2013.

[9] SILENCE Project. Practitioner Handbook for Local Noise Action Plans; 2007.

[10] World Health Organization. Environmental Noise Guidelines for the European Region; 2018.

[11] World Health Organization. Burden of disease from environmental noise; 2011.

[12] CityHush 2011. Low noise road surfaces in urban areas, hotspot detection and cost benefit analysis; 2011.

[13] DEFRA. Environmental Noise: Valuing impacts on: sleep disturbance, annoyance, hypertension, productivity and quiet; 2014.

[14] D’Alessandro F, Schiavoni S. A review and comparative analysis of European priority indices for noise action plans. Sci Total Environ. 2015 Jun;518-519:290-301.

[15] Vida Manzano J, Almagro Pator JA, García Quesada R. Community response to environmental noise in Granada (Spain): An evaluation by means of a standardized social survey. INTERNOISE; 2019 Jun 16-19; Madrid Spain. 2019.

[16] CEDR. State of the art in managing road traffic noise: cost-benefit analysis and cost-effectiveness analysis; March 2017.

[17] Network Interest Group in Traffic Noise Abatment. Decision and cost/benefit methods for noise abatment in Europe; 2018.

[18] World Health Organitation. Global Health Estimates: Life expectancy and leading causes of death and disability. [Online]. 2019. Available from: https://www.who.int/data/gho/data/ themes/mortality-and-global-health-estimates
[19] Decreto Legislativo n.42. Disposizioni in materia di armonizzazione della normativa nazionale in materia di inquinamento acustico. 2017 Feb 17.

[20] Miccioli S, Finucci F, Murro R. Assessing project quality: A multidimensional approach. Adv Mat Res. 2014;1030-1032:2519-22.

[21] Moretti L, Di Mascio P, Bellagamba S. Environmental, Human Health and Socio-Economic Effects of Cement Powders: The Multicriteria Analysis as Decisional Methodology. Int J Environ Res Public Health. 2017 Jun;14(6):14.

[22] Kumar S, Vaidya OS. Analytic hierarchy process: an overview of applications. Eur J Oper Res. 2016:1-29.

[23] Cavallo B, D’Apuzzo L. A general unified framework for pairwise comparison matrices in multicriterial methods. Int J Intell Syst; 2009:377-98.

[24] Aruldoss M, Lakshmi TM, Venkatesan VP. A survey on multi criteria decision making methods and its applications. J Inf Syst. 2013:31-43.

[25] Saaty TL. The Analytic Hierarchy Process New York: McGraw Hill; 1980.

[26] Navrud S. The economic value of noise within the European Union - A review and analysis of studies. Acta Acust (Les Ulis). 2004:89.

[27] European Environmental Agency. Reported data on noise exposure covered by Directive 2002/49/EC. [Online]. 2017. Available from: https://www.eea.europa.eu/data-and-maps/data/dataon-noise-exposure-2/

[28] Decreto Presidente della Repubblica. Disposizioni per il contenimento e la prevenzione dell'inquinamento acustico derivante dal traffico veicolare, a norma dell'articolo 11 della L. 26 ottobre 1995, n. 447. 2004 Mar 30.

[29] ISTAT. Istituto nazionale di statistica. [Online]. 2017. Available from: https://www.istat.it/it/archivio/104317

[30] Decreto Ministeriale. Criteri per la predisposizione, da parte delle società e degli enti gestori dei servizi pubblici di trasporto o delle relative infrastrutture, dei piani degli interventi di contenimento e abbattimento del rumore. 2000 Nov 29.

[31] Lazio R. Regione Lazio. [Online]. 2018. Available from: https:// ceremsslazio.astralspa.it/ceremss/DatiStatistiche/FCD

[32] NADIA project. Noise reduction Action Plans; 2009.

[33] EN 15804. Sustainability of construction works - Environmental product declarations - Core rules for the product category of construction products; 2014.

[34] EnvironDec. Environmental Product Declaration. [Online]. 2018. Available from: https://gryphon4.environdec.com/syst em/data/files/6/17052/S-P-01749\%20EPD\%20Window\%20Syst em\%20(English\%20version).pdf

[35] Brero G, Garai F, Morandi F. Noise barriers: Environmental sustainability assessment. In Euronoise 2018; 2018; Crete, Italy.

[36] TTS Italia. L'impatto degli ITS per la riduzione di $\mathrm{CO}_{2} ; 2014$. 